\title{
Erratum to: Copulae in High Dimensions: An Introduction
}

Ostap Okhrin, Alexander Ristig and Ya-Fei Xu

\section{Erratum to:}

Chapter 13 in: W.K. Härdle et al. (eds.), Applied

Quantitative Finance, Statistics and Computing,

https://doi.org/10.1007/978-3-662-54486-0_13

In the original version of the book, the following links have to be newly included in the caption of Fig. 13.4 in Chapter 13. The erratum chapter and the book have been updated with the change. 